\title{
Drawn to life: realistic medical sketches in a community emergency department
}

\author{
Christopher Patey ${ }^{1}$ (D) Hasan Al-Obaidi ${ }^{2} \cdot$ Paul Norman $^{2} \cdot$ Thomas Heeley $^{3}$
}

Received: 10 December 2020 / Accepted: 23 December 2020 / Published online: 18 January 2021

(c) The Author(s), under exclusive licence to Canadian Association of Emergency Physicians (CAEP)/ Association Canadienne de Médecine d'Urgence (ACMU) 2021

Keywords Emergency medicine $\cdot$ Art $\cdot$ Newfoundland \& Labrador $\cdot$ Rural

\section{Then \& now: the art of medicine}

Is medicine an art, or a science? The duality of medicine is a classic musing, and often cause for reflection on the value of art to our discipline. Long before databases, imaging technology, and other modern conveniences, painstaking illustrations of anatomy and physiology by ancient Egyptians and philosophers [1] set a precedent for the value and benefit of art in medicine. Even today, many physicians use sketches to enhance the language of a chart, though often these illustrations are rough, crudely etched at the bottom of a document. Amid the demands of practice, true talent is required to depict charts with the care of a hand-crafted art piece - and the added attention can be particularly beneficial in emergency medical care. This is the case in a small community emergency department in eastern Newfoundland and Labrador, where a physician is bringing charts to life with vivacious sketch art.

"The practice of medicine is an art, not a trade; a calling, not a business; a calling in which your heart will be exercised equally with your head." -William Osler

Christopher Patey

Christopher.patey@med.mun.ca

1 Memorial University of Newfoundland, Discipline of Family Medicine, St. John's, NL, Canada

2 Carbonear General Hospital, Eastern Health, Carbonear, NL, Canada

3 Carbonear Institute for Rural Reach and Innovation by the Sea (CIRRIS), Carbonear General Hospital, Carbonear, NL, Canada

\section{Emergency department artist: a portrait of Dr. Hassan Al-Obaidi}

Dr. Hassan Al-Obaidi is a new Canadian, a physician, and a gifted illustrator whose realistic drawings of clinical charts have created a buzz in the ED at the Carbonear General Hospital in Newfoundland and Labrador. From a young age, Dr. Al-Obaidi taught himself to sketch as a form of relaxation that later provided crucial solace while serving as a physician who treated civilian casualties. Having endured the hardship of three wars in his native Iraq, Hassan brought his resourcefulness and stunning talent to the challenge of rural emergency practice. From fellow physicians to nurses, Hassan's vivid depictions have added intrigue to the chart review process among his colleagues, who also find that the illustrations add clarity for documentation, jumping from pages of typically rushed prose and grammar. His detailed renditions have had numerous benefits for the department and were even used as evidence in a claim process being reviewed by the College of Physicians and Surgeons of Newfoundland and Labrador. 


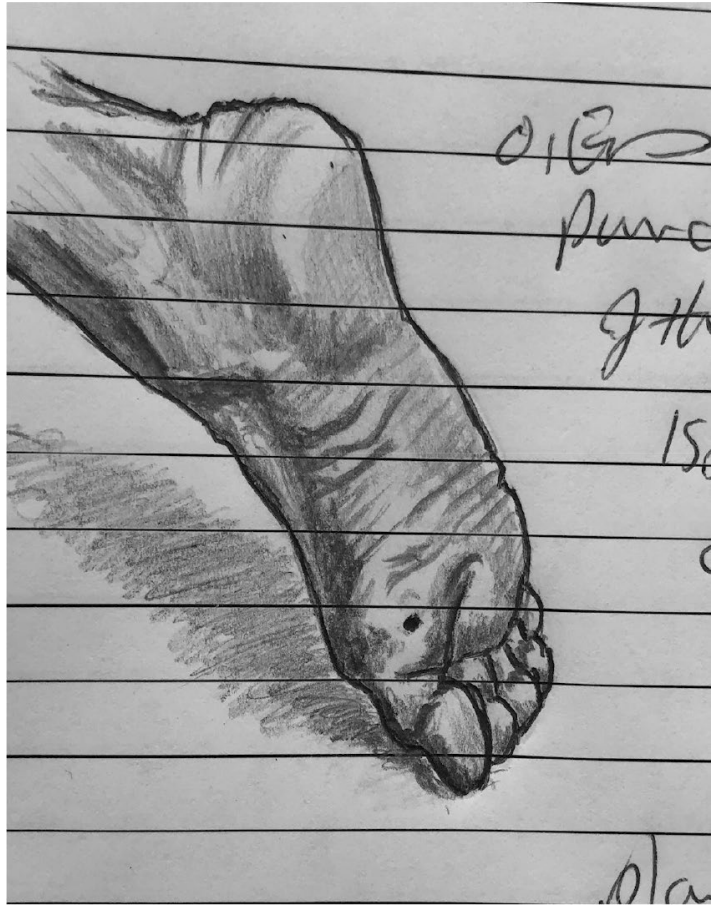

\section{Benefits to nursing-Paul Norman}

The Carbonear General Hospital ED is a fortunate corner of healthcare not yet entirely dominated by electronic charting. While pen and paper are still widely used for the essential task of documentation at the hospital, medical sketches were rare in our nursing documentation, that is until Dr. Al-Obaidi's crisp, shaded depictions became the awe of the emergency room. Nursing and clerical staff alike were inspired by the images of foreign bodies in eyes as well as appendage lacerations and began to embellish their own documents. Small sketches appeared in droves on triage notes, and in the main ED on ongoing registered nurse assessment sheets. Channeling artistic expression in the healthcare setting was infectious and led our team to wonder if the inevitable transition from paper to electronic charting might cause us to lose an opportunity to document patients' journeys in a most intimate, human form. Artistic expression has a way of providing an outlet to another world or a calming sense. Using sketch art as part of the ED documentation landscape can bring a sense of calm and stability to an otherwise chaotic environment. Furthermore, it is often difficult to describe an ED patient presentation in words; it is evident from the sketches showcased here how much more vividly an image can explain a patient's condition.

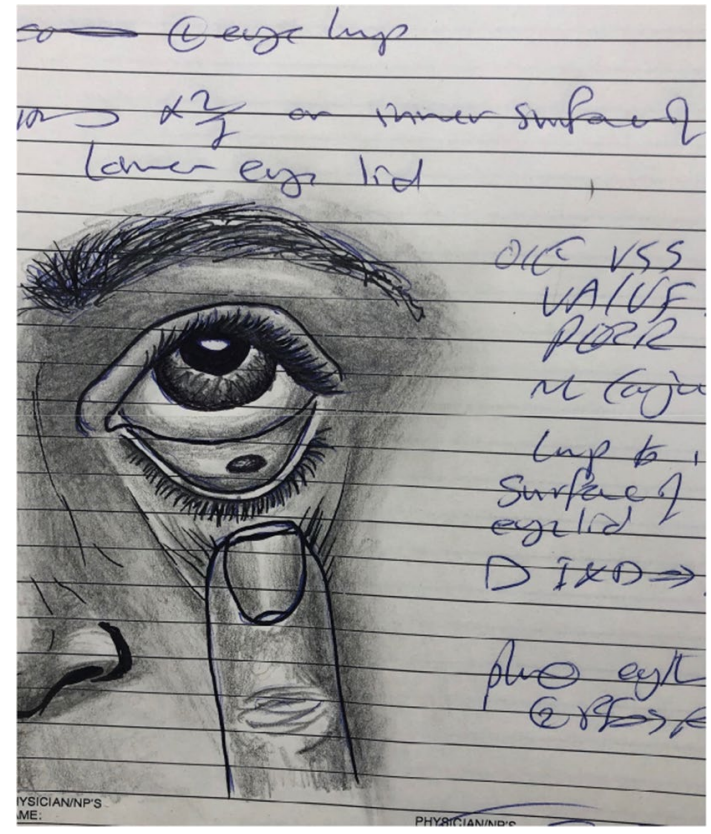

\section{Departmental benefits - Dr. Christopher Patey}

There are expected challenging components when appointed to site Clinical Chief of a rural ED. The increasing volume, and complexity of patients with the overcrowding of our departments leading to departmental backlogs, generates increasing patient complaints and physician burnout. Thankfully, there are rewards: the thankful patient who returns with a departmental gift, the new physician who stands out on a demanding case and observing the ED develop into a true team dedicated to providing the finest patient care. Then there are the inspirational moments you truly cherish. Seeking a better life in Canada, Dr. Al-Obaidi entered our ED physician world, quiet yet with unwaveringly focused. Quickly adapting to the turbulence and independence of rural emergency practice, he worked diligently to see everyone as effectively as possible. With his superior adaption arose a further brilliance. His superior efficiency in the department leads to increased time for one of his true passions that graced our charts. His medical sketches started to appear in my chart reviews: the recheck of cellulitis or the suture removal of one of his previous lacerations. Nurses raved and colleagues were equally inspired. His dedication to perfection was yet another symbol, a badge, for how well our department functioned. It was a subtle, yet transformative priceless impact that his artistic skills proved to be invaluable inspiration element of our ED. 


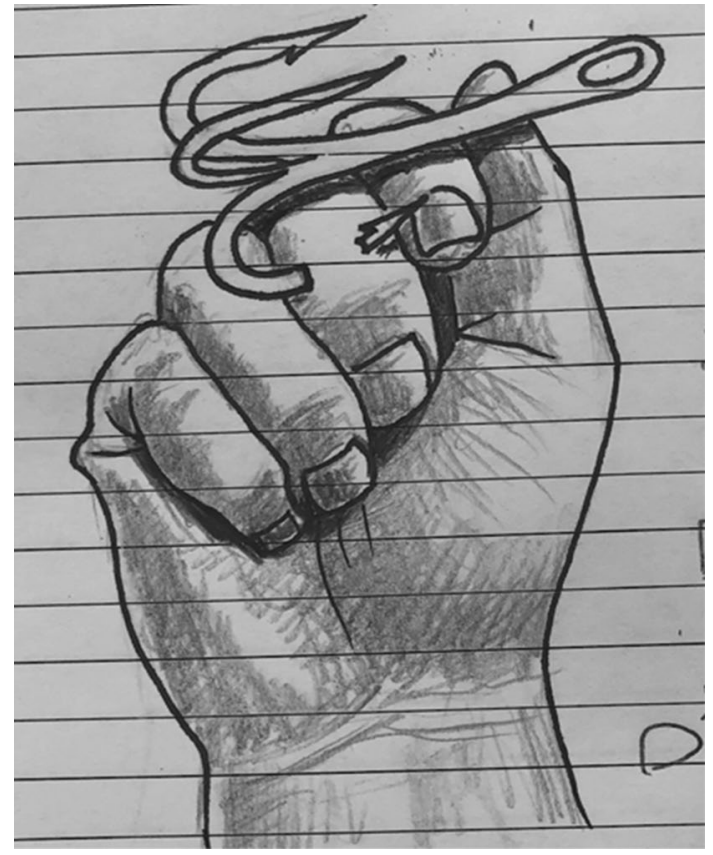

\section{Conclusion}

Using artistic expression to describe the trials of everyday life in healthcare, while not new, is certainly something that seems to be disappearing. It is the hope of this paper that the incredible sketch art of Dr. Hasan Al-Obaidi will bring as much joy and inspiration to the readers of this medical journal, as it has to the staff and any other independent reviewer of his charts. Dr. Al-Obaidi's continued work, with pride, precision and efficiency, is remarkable when you have the privilege to review these detailed sketches. Is it possible that electronic medical records of the future could incorporate the use of new electronic tools that have made digital art comparable in beauty to a pen and paper? We certainly hope so.

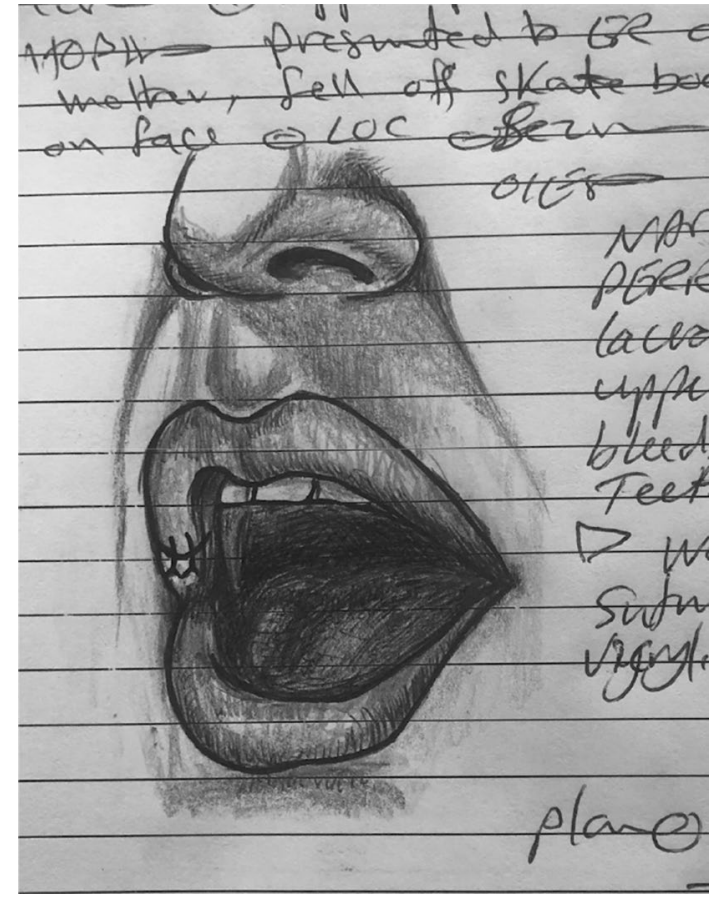

\section{Lessons learned}

- Inspiration can come in many subtle ways.

- The work of one can impact many.

- Take the moment to inspire, and to be inspired.

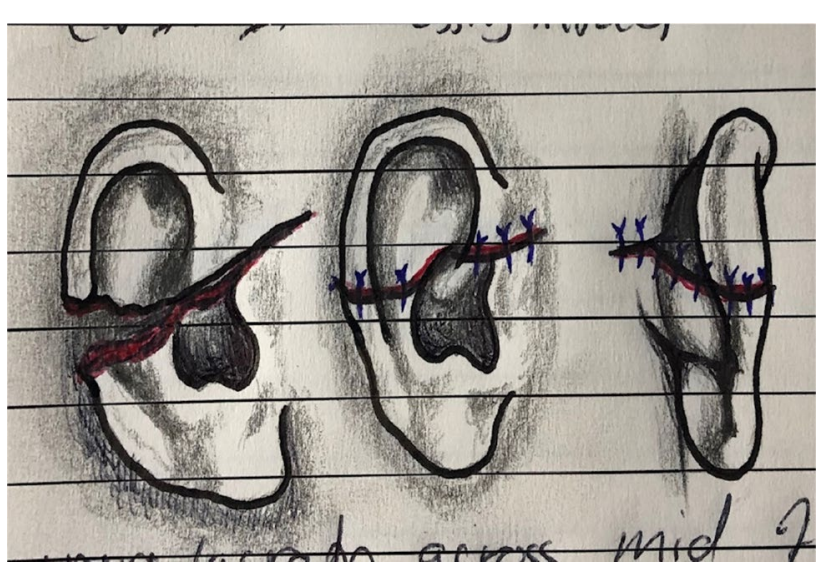

\section{Compliance with ethical standard}

Conflict of interest The authors declare that they have no conflict of interest and this research was not financially supported.

\section{Reference}

1. Loechel WE. The history of medical illustration. Bull Med Libr Assoc. 1960;48(2):168. 